\title{
How to Track Bacteria
}

\section{Citation}

Berg, Howard C. 1971. "How to Track Bacteria." Review of Scientific Instruments 42 (6): 868.

\section{Published Version}

doi:10.1063/1.1685246

\section{Permanent link}

http://nrs.harvard.edu/urn-3:HUL.InstRepos:12242820

\section{Terms of Use}

This article was downloaded from Harvard University's DASH repository, and is made available under the terms and conditions applicable to Other Posted Material, as set forth at http:// nrs.harvard.edu/urn-3:HUL.InstRepos:dash.current.terms-of-use\#LAA

\section{Share Your Story}

The Harvard community has made this article openly available.

Please share how this access benefits you. Submit a story.

\section{Accessibility}




\title{
How to Track Bacteria*
}

\author{
Howard C. BERg \\ Department of Molecular, Cellular and Developmental Biology, University of Colorado, Boulder, Colorado 80302
}

(Received 25 January 1971)

\begin{abstract}
A microscope is described which automatically remains focused on individual motile bacteria. The container in which the bacteria are suspended is moved in such a way that the position of a given organism remains fixed; $x, y$, and $z$ drive signals provide a measure of its displacement relative to the suspension medium. Records are shown of the motion of Escherischia coli.
\end{abstract}

\section{INTRODUCTION}

B ACTERIA respond to changes in their surroundings by modifying the way in which they swim. ${ }^{1}$ The purple bacteria reverse their direction on encountering the dark. ${ }^{2}$ A variety of species accumulate in favorable chemical environments ${ }^{3}$ by avoiding the unfavorable ones. $^{4,5}$ Response to light (phototaxis) is thought to be tightly coupled to photosynthesis, ${ }^{6}$ but response to chemicals (chemotaxis) appears to be triggered by specific sensors on the surface of the cell. ${ }^{7}$ It is not known how these sensors are linked to the motile apparatus. The hydrodynamics of flagellar propulsion is clear, ${ }^{8}$ but the chemical means are not. ${ }^{9}$ It seems realistic to suppose that the molecular basis for behavior can be understood in bacteria because bacteria are relatively simple cells amenable to genetic manipulation, and that the principles which emerge will be relevant to sensory processes in higher organisms as well.

The present work is aimed at resolving a major problem encountered in studies of bacterial motion, that of observation. Most bacteria are quite small (Escherischia coli, for example, are about $10^{-4} \mathrm{~cm}$ in diameter by $2 \times 10^{-4} \mathrm{~cm}$ long) and they can swim as fast as $\mathbf{5 0}$ diameters/sec. The depth of field is shallow in a microscope at magnifications high enough for close observation, so they can swim out of focus in a fraction of a second. If bacteria are confined in a small container, their motion is perturbed (E. coli, for example, tends to adhere to the container walls or to

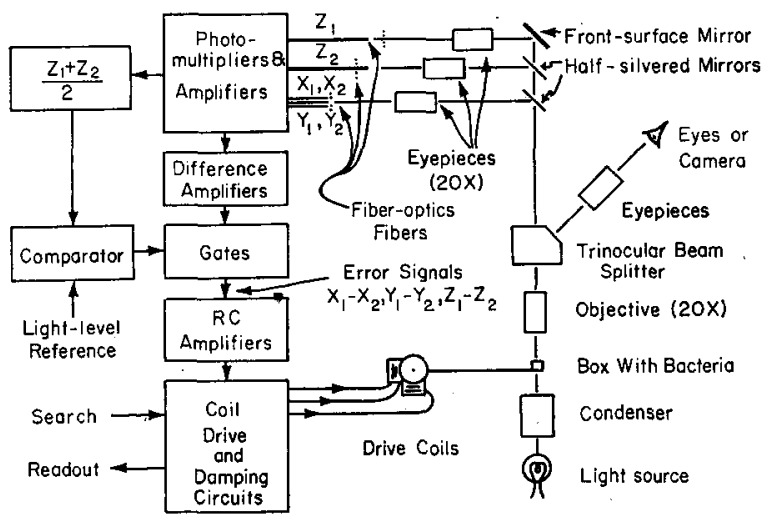

FIG. 1. Schematic diagram of the tracking microscope. swim in circles). As a consequence, most studies have been made of individual cells of the larger species, e.g., Spirillum volutans, ${ }^{10}$ which happen to be in the field and in focus, or of bulk accumulations. ${ }^{11,12}$ The microscope described here automatically keeps a bacterium the size of $E$. coli in focus in the center of the field and provides electrical signals which are a measure of its position relative to the suspension medium. The tracking range is about $1 \mathrm{~mm}$ in any direction; the readout is accurate to about 1 bacterial diameter.

\section{DESCRIPTION OF THE APPARATUS}

The instrument is shown schematically in Fig. 1. A box containing the bacteria is mounted between a long working distance phase contrast condenser and a $20 \times$ dark field objective (Nikon) on an electromechanical transducer. The beam emerging from the top of the trinocular (the camera tube) is split so that three images of the bacterium being tracked fall on six fiber optics fibers (a plastic material available from Edmund Scientific Company). Each fiber leads to a separate photomultiplier. An observer looking along the beam sees the $z_{1}$ and $z_{2}$ fibers superimposed on the center of the array $x_{1}, x_{2}, y_{1}$, and $y_{2}$ (Fig. 2). The diameters of the fibers are all the same, roughly equal to the width of the image of the bacterium. The three eyepieces are positioned so that the image is in focus on $x_{1}, x_{2}, y_{1}$, and $y_{2}$ but slightly out of focus (fuzzed out) on both $z_{1}$ and $z_{2}$; the planes in which the images are in focus are indicated in Fig. 1 by the dotted lines. When the bacterium swims in the $+z$ direction (toward the objective), its image sharpens on $z_{1}$ and fuzzes out more on $z_{2}$; therefore, more light is transmitted by $z_{1}$ than by $z_{2}$. When the bacterium moves toward the condenser, the reverse is true. When it moves in the $+x$ direction, more

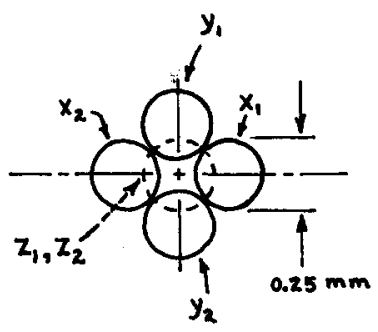

FIG. 2. Composite view of the ends of the fiber optics fibers. 
light is transmitted by $x_{1}$ than by $x_{2}$, and when it moves in the $-x$ direction, more light is transmitted by $x_{2}$ than by $x_{1}$; similarly for $y$. Signals proportional to the errors in displacement are obtained by taking the difference of the photomultiplier amplifier outputs $x_{1}-x_{2}, y_{1}-y_{2}$, and $z_{1}-z_{2}$. These signals are filtered and amplified (see Fig. $3^{13}$ ) and used in negative feedback loops to control the position of the box; the image of the bacterium remains locked to the fibers. When the bacterium moves beyond the range of the drive coils, control is no longer possible; the amount of light reaching the photomultipliers falls to the dark field level. This state is sensed by the comparator (Fig. 1), which grounds the $\mathrm{RC}$ amplifier inputs, thereby returning the box to its center position. When another organism swims into range or when a search for one is successful, the comparator closes the feedback loops and the system tracks once again.

The electromechanical transducer is shown in Fig. 4. Its equilibrium position is determined for each axis by the balance between the electromagnetic force on a coil suspended in the annular gap of a cylindrical magnet and the net elastic force due to the differences in the lengths of two springs. The displacement is proportional, to a first approximation, to the current in the coil. The coil is mounted on a tungsten rod $(0.05 \mathrm{~cm}$ in diam), which is stiff and nonmagnetic, and the springs are made of steel. The platform which carries the box is mounted on a tungsten strut. The ring magnet (shown crosshatched) is Hyflux Alnico V (Indiana Steel Products CG-705), and the pole pieces are Armco ingot iron. The gap is wide enough to allow the coil to move radially as well as axially; the field in the gap is about $2200 \mathrm{G}$.

The transducer meets three design criteria. (1) It fits on the microscope (a Nikon $\mathrm{S}-\mathrm{Ke}$ ); (2) its resonant frequencies are greater than $50 \mathrm{cps}$ (about $80 \mathrm{cps}$ for the translational modes, 120 for the rotational ones); and (3) all modes are critically damped (or nearly so). If the resonant frequencies of the transducer are not higher than the frequencies of the error signals, the motion of the transducer will be out of phase with these signals, and the system will oscillate rather than track. Because a bacterium can swim about 50 diameters/sec and its image is about

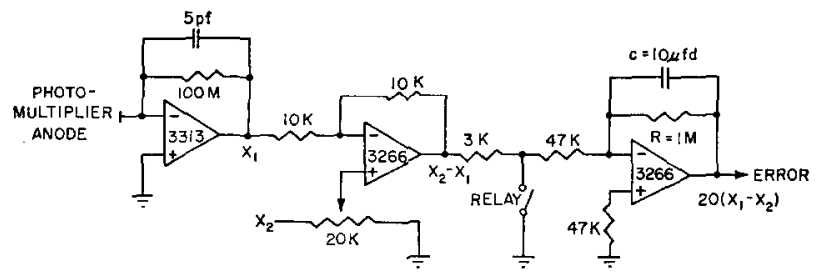

FIG. 3. The photomultiplier, difference, and RC amplifiers, respectively. The photomultiplier is an RCA C7164R with a $3.8 \mathrm{~cm}$ o.d., $6.4 \mathrm{~mm}$ i.d., $8.0 \mathrm{~mm}$ thick ceramic ring magnet taped to its face; see Ref. 13. The operational amplifiers are from Burr-Brown Research Corp.; 3313 has an FET input, 3266 a bipolar transistor input. The relay (gate) is controlled by the comparator (Fig. 1).
FIG. 4. Scale drawing of the electromechanical transducer as seen from above. Only the $x$ axis is shown in its entirety.

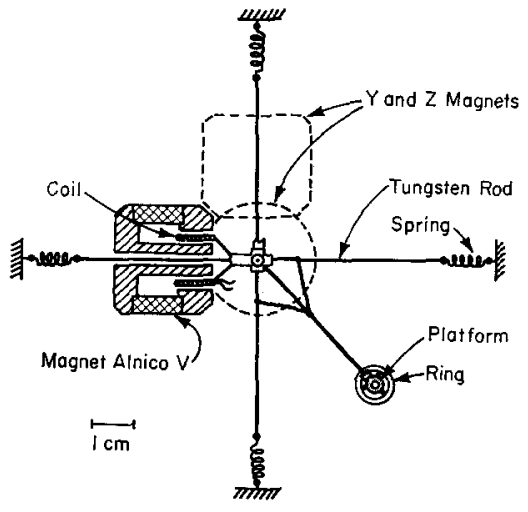

the size of the detector, the error signals can change appreciably in 1/50 sec: the resonant frequencies must be greater than $50 \mathrm{cps}$. If the modes are critically damped, the box can be made to move from one point to another in a minimum amount of time without overshooting. The first criterion was met empirically, the second by keeping the mass and moments of inertia small and the suspension stiff; the third proved more difficult to satisfy.

Most of the translational damping arises from eddy current losses in the coil forms, which are aluminum. The remainder is provided by adding current to each coil in phase with its velocity. The coils have two windings (of No. 38 Formvar insulated copper wire), a primary of 310 turns and a secondary of 70 turns. The current in the primary serves to displace the transducer, the emf in the secondary to gauge its velocity. Part of the emf in the secondary is due to the mutual inductance between the windings; this part is subtracted out by comparing the emf in the moving coil with the emf in one which is fixed (Fig. 5). In this figure, the induced emf's are denoted $\mathrm{f}$ and $\mathrm{m}$, for fixed and moving, respectively. An operational amplifier (not shown) is used to generate a voltage $A(B f-m) . B$ is chosen so that $B f-m=0$ when the transducer is held fixed; $A$ is adjusted so that the damping is critical. The feedback (in Fig. 5) is such that the voltage at READOUT is proportional to the sum of the voltages ERROR, SEARCH, and $A(B \dot{f}-m)$. The voltage at READOUT determines the current through the $3 \Omega(10 \mathrm{~W})$ resistor and, hence, the current through the moving coil primary. The deflection of the transducer is limited by the current which this coil can tolerate; the coils run hot

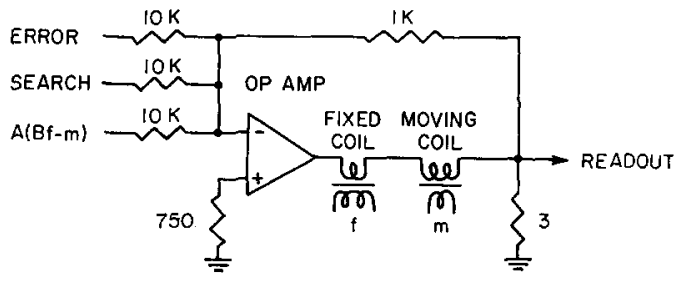

Frg. 5. The coil drive and damping circuit. The operational amplifer is a $\mu$ A 709 followed by a power booster built from discrete components. 


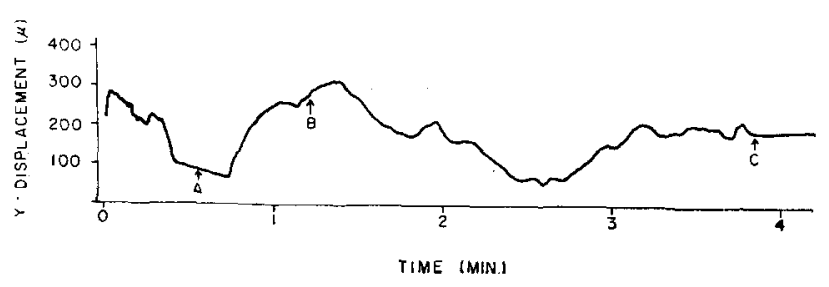

FIG. 6. A strip chart recording of the $y$ displacement (the $y$ readout voltage) of an $E$. coli, 3 April 1970 . The tracking began at 0 min. The $x, y$, and $z$ voltages were stored on an oscilloscope during the interval $\mathrm{A}$ to B; an analysis of these data is shown in Fig. 7. At $\mathrm{C}$ the bacterium collided with one which was not swimming, and the microscope elected to follow that one instead.

at high currents and change their resistances, so a current injection circuit of the sort shown in Fig. 5 is essential. In practice, the contribution of the term $A(B f-m)$ is quite small; the velocity is of order $10^{-2} \mathrm{~cm} / \mathrm{sec}$.

When the transducer rotates about its axes, the coils either rotate about their axes or move sideways; therefore, no electromagnetic forces are generated. The rotational modes are damped by viscous drag: A ring (an annular disk) mounted below the platform (Fig. 4) is immersed in an annular pool of oil (Dow Corning 510 fluid, $1000 \mathrm{cS}$ ). The oil has comparatively little effect on the translational modes.

\section{PERFORMANCE}

The instrument was tested with an $E$. coli K12 strain. ${ }^{14}$ The motion of one such organism is depicted in Fig. 6 . Only a single channel strip chart recorder was available; it was used to monitor the $y$ displacement. The data from all three axes could be recorded for short intervals on a storage oscilloscope; this was done during the period A to B (Fig. 6). Figure 7 shows the progress of the organism during this time. It swam toward the origin (chosen to coincide with the point of abrupt change in direction) at a fairly uniform speed of $4 \mu / \mathrm{sec}$ and then turned around (or backed up) and increased its speed to $40 \mu / \mathrm{sec}$. From the appearance of this curve one is tempted to assume that the bacterium kicked off and coasted away from the origin; however, viscous forces are so great that an E. coli traveling $40 \mu / \mathrm{sec}$ could coast no more than about $10^{-4} \mu !^{8}$ At C (Fig. 6) the organism was seen (through the binocular, Fig. 1) to collide with one which was not swimming; the microscope locked onto this bacterium and the other swam out of focus.

The scene through the binocular is extraordinary. The bacterium being tracked seems to be stuck to the center of the field, turning this way and that trying to free itself, while the other bacteria drift in and out of focus, then to and fro, in apparent synchrony. If the bacterium being tracked is long, it seems to be stuck at one end and then at the other; the microscope will track on any part. It follows that the readout is accurate at best to within one bacterial length. If the bacterium is tumbling while it swims, however, this is apparent from the readout voltages, which show a series of steps at the tumbling frequency. The readout is about $2 \mathrm{mV} / \mu$, and the rms noise level is much less than $1 \mathrm{mV}$.

Bacteria may wobble in step with the flagellar beat. The error signals should have components at this frequency, somewhere around $50 \mathrm{cps}$. These components were looked for in the outputs of the difference amplifiers (Figs. 1 and 3), but they were not seen. At low light levels the signal-to-noise ratio at this point is poor; at high light levels the transducer oscillates at low amplitude; the microscope still tracks, but signals due to the oscillation dominate the difference amplifier outputs. The search will be repeated if this instability can be eliminated.

The amount of information collected in tracking just one bacterium is so great that strip chart recording is not very convenient; in the future, the data will be converted to digital form and written on computer compatible magnetic tape.

\section{DISCUSSION}

In the past, the use of the microscope in studies of bacterial motility has been comparatively ineffective..$^{15}$ Ogiuti, ${ }^{16}$ for example, clocked the passage of bacteria over a known distance, while Shoesmith ${ }^{17}$ counted the number which passed a small aperture in unit time. ${ }^{18}$ More can be learned from the analysis of movies, as long as the bacteria remain in focus, but the work is tedious. Tracking provides a record of the displacement of a bacterium over a much longer period of time. The method does not give information about the movement of flagellar bundles, per se, but this information could be obtained by simultaneous cinematography.

Any object can be followed which appears bright against a dark background if its speed is less than about 50 object diameters/sec and if its net displacement is less than about $1 \mathrm{~mm}$. If the object is microscopic, so that its propulsion is governed by viscous rather than inertial forces, ${ }^{8}$ the motion of the box will not significantly affect the way in which it moves through the medium. ${ }^{19}$ Net displacements larger than $1 \mathrm{~mm}$ could be accommodated if the transducer were redesigned, easily so if slower

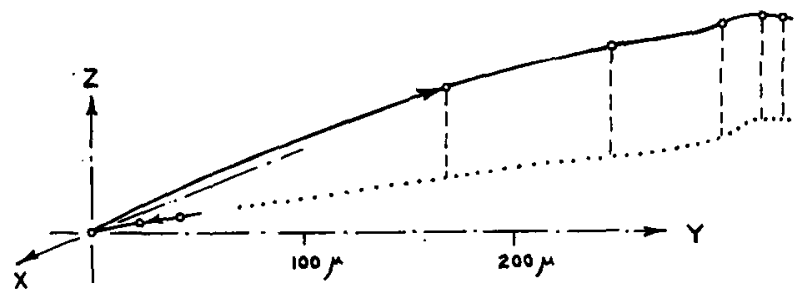

Fig. 7. A plot of the maneuver executed by the bacterium of Fig. 6 during the time interval $A$ to $B$. The arrows indicate the direction of motion. Each segment of the path is $5 \mathrm{sec}$ long. The dotted line is the projection of the path on the $x-y$ plane. 
tracking rates were adequate. Delbrück and Foster, for example, use long range hydraulic pistons in a system for tracking the sporangiophore of Phycomyces, a macroscopic object which moves much more slowly than a bacterium..$^{20}$ Electronic means have been devised by others for analyzing the motion of rapidly swimming eucaryotic organisms, but only in two-dimensional projection. ${ }^{21}$

\section{ACKNOWLEDGMENTS}

I thank Julius Adler and Costas Papaliolios for their comments on the manuscript.

* Work done in the Department of Biochemistry and Molecular Biology, Harvard University, Cambridge, Mass. 02138, funded in part by a PHS Biomedical Sciences Support Grant. Publication costs were covered by a grant from the Research Corporation.

1 For a review, see C. Weibull, Bacteria 1, 188 (1960).

2 T. W. Engelmann, Arch. Ges. Physiol. Pflüger's 30, 95 (1883).

${ }^{3} \mathrm{~W}$. Pfeffer, Untersuch. Botan. Inst. Tübingen 1, 363 (1884); 2, 582 (1888).

${ }^{4}$ W. Rothert, Flora 88, 371 (1901).

${ }^{5}$ H. S. Jennings and J. H. Crosby, Amer. J. Physiol 6, 31 (1901).

${ }^{6} \mathrm{R}$. K. Clayton in Photophysiology, edited by A. C. Giese (Academic, New York, 1964), Vol. II, p. 51.
7 J. Adler, Science 166, 1588 (1969).

8 G. I. Taylor, Proc. Roy. Soc. (London) A211, 225 (1952).

${ }^{9}$ For a review, see R. N. Doetsch and G. J. Hageage, Biol. Rev. 43,317 (1968)

io P. Metzner, Jahrb. Wiss. Botan. 59, 325 (1920).

11 R. K. Clayton, Arch. Microbiol. 27, 311 (1957).

$12 \mathrm{~J}$. Adler, Science 153, 708 (1966).

$13 \mathrm{~J}$. A. Topp, H. W. Schrötter, H. Hacker, and J. Brandmüller, Rev. Sci. Instrum. 40, 1164 (1970).

${ }_{14}$ RFS 630 , kindly supplied by Robert F. Schleif. A culture was grown overnight in yeast extract tryptone, diluted 1:50, grown another $2 \mathrm{~h}$ to $2 \times 10^{8}$ cells $/ \mathrm{ml}$, and mixed with Adler's chemotaxis medium (see Ref. 7, note 6) at a dilution of roughly $1: 1000$, a procedure adequate for the purpose at hand.

${ }^{15}$ See the Introduction here, Sec. II of Ref. 9 , and the discussion in J. Adler and M. M. Dahl, J. Gen. Microbiol. 46, 161 (1967).

${ }_{16}$ K. Ogiuti, Jap. J. Exp. Med. 14, 19 (1936).

17 J. G. Shoesmith J. Gen. Microbiol. 22, 528 (1960).

${ }^{18}$ This technique has been used to greater advantage in studies of spermatozoa; see R. Rikmenspoel, Rev. Sci. Instrum. 35, 52 (1965).

${ }^{19}$ With $E$. coli, for example, the acceleration of the box is at most about $10^{4} \mu / \mathrm{sec}^{2}$, an acceleration which changes the sedimentation velocity of the organism by no more than about $10^{-4} \mu /$ sec.

${ }^{20}$ M. Delbrück and K. Foster, private communication (1970).

$21 \mathrm{~W}$. G. Hand, P. A Collard, and D. Davenport, Biol Bull. 128, 90 (1965). In their latest scheme, a fixed chamber is viewed through a microscope by a television camera, and the output is analyzed by a computer [D. Davenport, G. J. Culler, J. O. B. Greaves, R. B. Forward, and W. G. Hand, IEEE Trans. Bio-Med. Eng. BME17, $230(1970)$ ]. For a brief discussion of the use of scanning microscopes in the study of stationary objects, see P. G. Stein, Anal. Chem. 42, 103A (1970). 